\title{
波浪中を拘束されて前進する物体に働く 抵抗増加に関する研究
}

\author{
正員 肥 後 靖* 正員 河 文 根** \\ A Study on Added Resistance of a Restrained Body with Forward Speed in Waves
}

by Yasushi Higo, Member Mun Keun Ha, Member

\begin{abstract}
Summary
Added resistance can be usually calculated by a method of the pressure integral on the wetted surface of a body or the momentum relation of the control volume. In our previous study, the values of Maruo's formula based on the latter for a surface-piercing body with linearized condition (so-called NeumannKelvin problem) was not in good agreement with the results of the former.

In this study, inconsistancy of the Neumann-Kelvin problem is considered as a reason of its disagreement. For the validation of added resistance by the upper two methods, new terms in Maruo's formula need to be considered which are caused by the inconsistency in the rate of change of momentum and energy flux arising from the intersection in the surface-piercing body with forward velocity. Diffraction problem of a vertical circular cylinder which is a column of ocean structure is taken as an example, and first order fluid force and added resistance in regular waves are calculated. With respect to the added resistance, the result of modified formula based on Maruo's momentum theory in NeumannKelvin problem agrees well with that of the pressure integral method.

The calculated result is compared with the measured one. First order fluid forces agree well. The results of added resistance generally show good agreement, but the accuracy of results needs to be improved as Froude number increases.
\end{abstract}

\section{1. 緒言}

波浪中を一定速度で航行する水面貫通物体に作用する抵 抗增加に関する著者等の以前の研究 ${ }^{1}$ に扔いて, 丸尾教授 の抵抗増加公式 (2) 用いて求めた抵抗増加と，物体まわり に直接圧力積分 ${ }^{3)} し て$ 求めた抵抗増加の值に差異があるこ とを示した。この原因として数值計算の精度の問題がある ことを指摘していたが，その後の研究で，鉛直円柱のよう な肥大物体の場合は水面近傍での要素と線積分に寄因する 特異性によって数値計算精度が悪化することが確認され， グリーン関数の積分計算精度の相当な向上が見込まれるよ うになった4”。

一方，柏木によってエネルギー原理において NeumannKelvin 問題の inconsistency が顕在化することが指摘 ${ }^{5}$ さ れたが, 上記の不一致は数値計算精度のためだけではなく，

$*$ 広島大学工学部

**広島大学大学院工学研究科
この種の問題に存在する不斉合性に由来することも考えら れる。理論的には運動量理論を用いた抵抗増加と直接圧力 積分によるものとの間に差異があるはずがなく, 従って数 值計算の信頼性を調査する際に，このような不斉合性によ る不一致があってはならない。

本研究では Neumann-Kelvin 問題において数値計算の 妥当性を検討するために圧力を物体没水表面上で積分する ことによって求めた抵抗増加と, 運動量理論を適用するこ とによって無限遠でのポテンシャル挙動から求めたものが 一致するかどうかを調べる。問題の簡単化のため diffraction 問題を取り扱って解析を行なったが, 結局水面 貫通物体でも速度がない場合には両者が一致するが, 速度 がある場合には自由表面と物体の交線上に NeumannKelvin 問題の不斉合性に由来する付加項が必要であるこ とがわかった。この項の抵抗増加に対する数値寄与度につ いて検討するために鉛直円柱を計算モデルとして数值計算 を行ない，また実験とも合わせて比較検討を行った。 


\section{2. 運動量理論による抵抗増加}

本研究の主題は丸尾教授の抵抗増加理論を NeumannKelvin 問題に適用した場合の検討を行なうことであるの で, 理論の展開は丸尾教授のものに従っている。言うまで もなく, consistentな理論（例えば thin ship theory とか 速度が 0 の場合等々）では丸尾教授の結果と一致するはず であり，本考察の妥当性もそれによって checkできる。

Fig. 1のように境界面 $S$ によって囲まれた領域での $x$ 方向の運動量の時間変化率は Eulerの運動方程式から,

$$
\frac{d M_{x}}{d t}=\iint_{s}\left\{P n_{x}+\rho u\left(\frac{\partial \Phi}{\partial n}-U_{n}\right)\right\} d S
$$

と書くことができる。ここで $u$ は流体粒子の $x$ 方向の速度 成分， $P$ は圧力， $U$ は一様流の速度， $n$ は境界面上に立て た流場内向き単位法線ベクトルである。

本研究においては問題の簡単化のため，物体は固定され て抢り波による動摇はないもの, 即ち diffraction 問題のみ 扱うことにする。

( 1 ) 式の $\Phi$ は流場の速度ポテンシャルを表わし,

$\Phi(x, y, z, t)=\Phi_{0}(x, y, z)+\Psi(x, y, z, t)$

$=U\{-x+\varphi(x, y, z)\}+\operatorname{Re}\left\{\phi(x, y, z) e^{i \omega_{e} t}\right\}$

とおく。ここで， $\Phi_{0}$ は定常ポテンシャル， $\varphi$ は定常攪乱ポ テンシャル， $\phi$ は diffraction ポテンシャル $\phi_{D}$ と入射波ポ テンシャル $\Phi_{I}$ の和であり，また $\omega_{e}$ は出会い周波数を表わ ᄂ,

$\omega_{e}=\omega-K U \cos \chi \quad(\chi=0:$ 追い波 $)$

の関係がある。さらに $\omega$ は入射波の円周波数， $\chi$ は波の入 射角， $K=\omega^{2} / g$ である。

(2)式で表わされる速度ポテンシャルは自由表面条件

$$
\left.\begin{array}{l}
\frac{\partial \varphi}{\partial z}=-\frac{1}{K_{0}} \frac{\partial^{2} \varphi}{\partial x^{2}} \\
\frac{\partial \Psi}{\partial z}=-\frac{1}{g}\left\{\frac{\partial^{2} \Psi}{\partial t^{2}}-2 U \frac{\partial^{2} \Psi}{\partial t \partial x}+U^{2} \frac{\partial^{2} \Psi}{\partial x^{2}}\right\}
\end{array}\right\} \begin{array}{r}
\text { on } z=0 \\
\left(S_{F_{0}}\right)
\end{array}
$$

を満足し，また水面変位は

$$
\begin{aligned}
& \zeta=\zeta_{0}+\tilde{\zeta} \\
& \left.\zeta_{0}=\frac{1}{K_{0}} \frac{\partial \varphi}{\partial x}, \quad \tilde{\zeta}=-\frac{1}{g}\left\{\frac{\partial \Psi}{\partial t}-U \frac{\partial \Psi}{\partial x}\right\}\right\} \text { at } z=0
\end{aligned}
$$

となる。ここで $K_{0}=g / U^{2}$ である。一方, 圧力は Bernoulli 定理から

$$
\begin{aligned}
P & =-\rho \frac{\partial \Phi}{\partial t}-\frac{1}{2} \rho(\nabla \Phi)^{2}-\rho g z+\frac{1}{2} \rho U^{2} \\
& =-\rho\left\{\Psi_{t}-U \Psi_{x}+U \nabla \varphi \nabla \Psi+\frac{1}{2}(\nabla \Psi)^{2}\right\} \\
& +\rho U^{2}\left\{\varphi_{x}-\frac{1}{2}(\nabla \varphi)^{2}\right\}-\rho g z
\end{aligned}
$$

と書ける。式(4)，(5)においては $\varphi$ のオーダーを $\epsilon$ とし た上で, $0\left(\epsilon^{2}\right)$ 以上の項を無視しているが，(6)式において はその種の省略はなされていない。

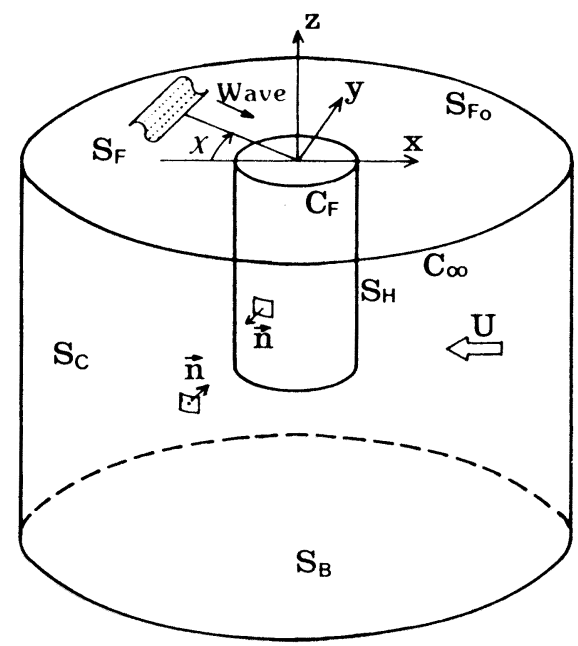

Fig. 1 Coordinate system and boundary surface

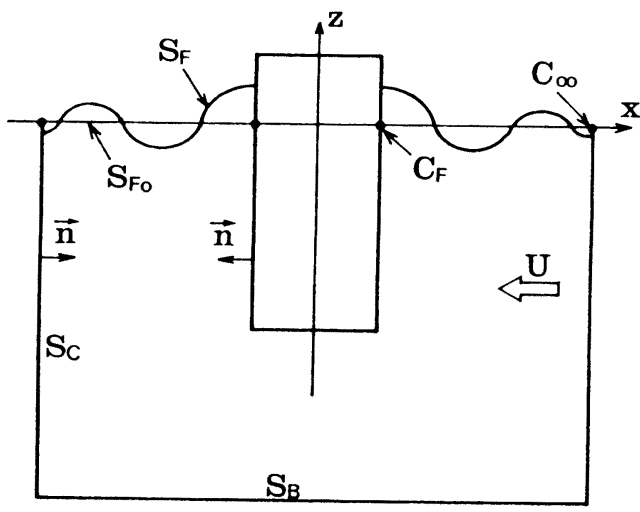

Fig. 2 Boundary surface

以後の展開において境界はFig. 1 及びFig. 2 で示すよ うに $z=0$ の平面と無限遠の円筒検查面, 物体境界並びに 水底に囲ま机た境界を固定境界と呼ぶことにし，下付添字 “0”を付けて $S_{F_{0}}, S_{C_{0}}, S_{H_{0}}, S_{B_{0}}$ と表沶す。また水面変化を考 慮した境界面を移動境界と呼ぶことにし $S_{F}, S_{C}, S_{H}, S_{B}$ と 表わす。移動境界を使用した場合は Neumann-Kelvin 問題 の不斉合性からエネルギー原理に矛盾が生じることが柏 木 ${ }^{5)}$ によって指摘されているが，質量保存則にも同様の矛 盾があることが等者等によって示されている゙。るそれに対 して固定境界を使用した場合は Bernoulli 压力方程式在使 用する限りに扔ては与えられた境界条件り下で求めた速 度ポテンシャルを(1)式に代入しても何ら矛盾が生じな い。従って以後の理論展開には固定境界を用いることにす る。

\section{1 固定境界における運動量理論}

Fig. 2 のように $z=0$ の水面下部での固定境界 $S_{C_{0}}, S_{F_{0}}$, $S_{H_{0}}$ で囲ま机た領域での境界条件は 


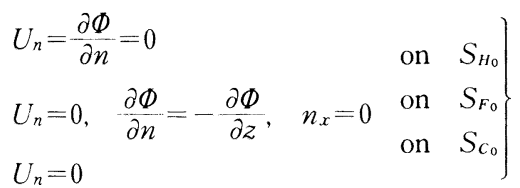

のようになり，（７）式の関係を用いると運動量変化率を表 わす式(1)は

$$
\begin{aligned}
\frac{d M_{x}}{d t}= & \iint_{S_{H 0}} P n_{x} d S+\iint_{S c 0}\left(P n_{x}+\rho \frac{\partial \Phi}{\partial x} \frac{\partial \Phi}{\partial n}\right) d S \\
& -\rho \iint_{S_{F 0}} \frac{\partial \Phi}{\partial x} \frac{\partial \Phi}{\partial z} d S
\end{aligned}
$$

と書ける。

本研究の目的は数值計算の妥当性の評価の基準として, 運動量理論展開の基本となる物体上の直接圧力積分と無限 遠での物理量を使用した結果が一致しているかどうかを調 査することにある。従って，本来の意味での流体力を考え る場合，物体上の wave elevationの影響を考慮した $S_{H}$ 上 での圧力積分を考えなけ机ばならないが，上記の意味，即 ち計算の validation という観点からならば $z \leq 0$ における 物体に㗢く流体力について検討してもさしつかえない。以 後の理論展開ではこのような理由で $S_{H_{0}}$, 即ち固定境界に 働く流体林つて考えているが，本来の流体力と区別す る意味で上付添字“””を付けることにする。

\section{1 .1 定常造波問題}

まず定常問題に対して考える。速度ポテンシャルに関す る(2)式と压力に関する $(6)$ 式において $\Psi=0$ とおけば定 常のそれぞれの值となる。特に圧力に関しては

$$
P_{0}=\rho U^{2}\left\{\varphi_{x}-\frac{1}{2}(\nabla \varphi)^{2}\right\}-\rho g z
$$

とおいて区別する。ここで固定境界面に囲まれた流場での 運動量の保存性から $d M_{x} / d t=0$ が成り立つので, 固定境界 に扮ける定常造波抵抗 $R_{0}^{\prime}$ は (4)，(8) 式より

$$
\begin{aligned}
R_{0}^{\prime}= & \iint_{S_{H 0}} P_{0} n_{x} d S=-\iint_{S_{c 0}}\left(P_{0} n_{x}+\rho \frac{\partial \Phi_{0}}{\partial x} \frac{\partial \Phi_{0}}{\partial n}\right) d S \\
& +\rho \iint_{S_{r 0}} \frac{\partial \Phi_{0}}{\partial x} \frac{\partial \Phi_{0}}{\partial z} d S \\
= & -\iint_{S_{c 0}}\left\{P_{0} n_{x}+\rho U^{2} \varphi_{x}\left(-n_{x}+\varphi_{n}\right)\right\} d S \\
& +\rho U \iint_{s_{c 0}} \frac{\partial \Phi_{0}}{\partial n} d S-\frac{\rho U^{2}}{K_{0}} \iint_{S_{r 0}}\left(-1+\varphi_{x}\right) \varphi_{x x} d S
\end{aligned}
$$

と表わされる。(10)式の有辺の第 2 項は Appendix A1 の 質量保存の関係を用いて書き換えることができる。さらに 第3 項を取り出してStokes 定理によって展開すると

$$
\begin{aligned}
I_{0} & =-\frac{\rho U^{2}}{K_{0}} \iint_{S_{F 0}}\left(-1+\varphi_{x}\right) \varphi_{x x} d S \\
& =-\rho U^{2}\left[\oint_{C_{r}}-\oint_{C_{\infty}}\right] \zeta_{0} d y+\frac{\rho g}{2} \oint_{C_{r}} \zeta_{0}^{2} d y \\
& +\frac{\rho g}{2} \int_{0}^{2 \pi} \zeta_{0}^{2} R n_{x} d y
\end{aligned}
$$

のように書き換えられるのでまとめて整理すると固定境界
における定常造波抵抗は

$$
\begin{aligned}
R_{0}^{\prime}= & -\rho U^{2} \int_{0}^{2 \pi} R d \theta \int_{-\infty}^{0}\left\{\varphi_{x} \varphi_{n}\right. \\
& \left.-\frac{1}{2}(\nabla \varphi)^{2} n_{x}-K_{0} n_{x} z\right\} d z \\
& +\frac{\rho g}{2} \int_{0}^{2 \pi} \zeta_{0}^{2} R n_{x} d \theta+\frac{\rho g}{2} \oint_{C_{F}} \zeta_{0}^{2} d y
\end{aligned}
$$

となる。ここで， $R$ は円筒検査面 $S_{C_{0}}$ の半径を表わす。

\section{1 .2 非定常造波問題}

次に非定常問題を考える。（8)式において両辺の周期平 均をとると問題の周期性より境界によって囲まれた領域で $\overline{d M_{x} / d t}=0$ となるので, 固定境界における非定常造波抵抗 $\tilde{R}^{\prime}$ は

$$
\begin{aligned}
\tilde{R}^{\prime}= & \iint_{S_{H 0}} \overline{P n_{x}} d S=-\iint_{S_{c o}} \overline{\left(P n_{x}+\rho \frac{\partial \Phi}{\partial x} \frac{\partial \Phi}{\partial n}\right)} d S \\
& +\rho \iint_{S_{F 0}} \frac{\overline{\partial \Phi}}{\partial x} \frac{\partial \Phi}{\partial z} d S
\end{aligned}
$$

と表わせる。ここで bar は周期平均することを意味してい る。（13) 式に速度ポテンシャルの定義式 ( 2 ) 及び圧力式 (6)を代入し, 質量保存の関係Appendix A1 を適用して 整理すると

$$
\begin{aligned}
& \tilde{R}^{\prime}=-\rho \iint_{S_{c 0}} \overline{\left\{-\frac{1}{2}(\nabla \Psi)^{2} n_{x}-\frac{U^{2}}{2}(\nabla \varphi)^{2} n_{x}-g n_{x} z\right.} \\
& \overline{\left.+\Psi_{x} \Psi_{n}+U^{2} \varphi_{x} \varphi_{n}\right\}} d S+\rho U^{2}\left[\oint_{C_{F}}-\oint_{C_{\infty}}\right] \zeta_{0} d y \\
& +\rho \iint_{S_{F 0}} \overline{\left\{U^{2}\left(-1+\varphi_{x}\right) \varphi_{z}+\Psi_{x} \bar{\Psi}_{z}\right\}} d S \\
& =-\rho \int_{0}^{2 \pi} R d \theta \int_{-\infty}^{0} \overline{\left\{\Psi_{x} \Psi_{n}-\frac{1}{2}(\nabla \Psi)^{2} n_{x}\right\}} d z \\
& -\frac{\rho}{g} \iint_{S_{F 0}} \overline{\Psi_{x}\left\{\Psi_{t t}-2 U \Psi_{t x}+U^{2} \Psi_{x x}\right\}} d S \\
& -\rho U^{2} \int_{0}^{2 \pi} R d \theta \int_{-\infty}^{0}\left\{\varphi_{x} \varphi_{n}-\frac{1}{2}(\nabla \varphi)^{2} n_{x}-K_{0} n_{x} z\right\} d z \\
& +\rho U^{2}\left[\oint_{C_{F 0}}-\oint_{C_{F \infty}}\right] \zeta_{0} d y \\
& -\frac{\rho U^{2}}{K_{0}} \iint_{S_{F 0}}\left(-1+\varphi_{x}\right) \varphi_{x x} d S
\end{aligned}
$$

と書き換えられる。ここで，(14)式の右辺第 2 項を取り出 し，定常問題に打ける(11) 式と同様にStokes 定理を適用 し水面変位の $(5)$ 式の関係を用いると

$$
\begin{aligned}
I= & -\frac{\rho}{g} \iint_{S_{F} 0} \overline{\Psi_{x}\left\{\Psi_{t t}-2 U \Psi_{t x}+U^{2} \Psi_{x x}\right\}} d S \\
= & -\frac{\rho g}{2} \oint_{C_{F}} \overline{\tilde{\zeta}^{2}} d y+\rho U \oint_{C_{F}} \overline{\bar{\zeta} \Psi_{x}} d y \\
& -\frac{\rho}{2 g} \int_{0}^{2 \pi} \overline{\left(\Psi_{t}-U \Psi_{x}\right)\left(\Psi_{t}+U \Psi_{x}\right) R} n_{x} d \theta
\end{aligned}
$$

のように変形することができる。式(11)，(15)の関係を用 いて固定境界における非定常造波抵抗を表わす(14)式は

$$
\begin{aligned}
\tilde{R}^{\prime}= & -\rho \int_{0}^{2 \pi} R d \theta \int_{-\infty}^{0} \overline{\left\{\Psi_{x} \Psi_{n}-\frac{1}{2}(\nabla \Psi)^{2} n_{x}\right\}} d z \\
& -\frac{\rho}{2 g} \int_{0}^{2 \pi} \overline{\left(\Psi_{t}-U \Psi_{x}\right)\left(\Psi_{t}+U \Psi_{x}\right) R} n_{x} d \theta \\
& -\frac{\rho g}{2} \oint_{C_{F}} \overline{\bar{\zeta}^{2}} d y+\rho U \oint_{C_{F}} \overline{\tilde{\zeta} \Psi_{x}} d y
\end{aligned}
$$




$$
\begin{aligned}
& -\rho U^{2} \int_{0}^{2 \pi} R d \theta \int_{-\infty}^{0}\left\{\varphi_{x} \varphi_{n}-\frac{1}{2}(\nabla \varphi)^{2} n_{x}\right. \\
& \left.-K_{0} n_{x} z\right\} d z \\
& +\frac{\rho g}{2} \int_{0}^{2 \pi} \zeta_{0}^{2} R n_{x} d \theta+\frac{\rho g}{2} \oint_{C_{F}} \zeta_{0}^{2} d y
\end{aligned}
$$

と書き換えられる。

\section{1 .3 固定境界に作用する抵抗増加}

$2.1 .1,2.1 .2$ 節から固定境界 $S_{H_{0}}$ の上に働く抵抗増加は $\Delta R^{\prime}=\tilde{R}^{\prime}-R_{0}^{\prime}$

$$
\begin{aligned}
= & \rho \int_{-\infty}^{0} d z \int_{0}^{2 \pi} \overline{\left\{\Psi_{x} \Psi_{R}-\frac{1}{2}(\nabla \Psi)^{2} \cos \theta\right\}} R d \theta \\
& +\frac{\rho}{2 g} \int_{0}^{2 \pi}\left(\overline{\left.\Psi_{t}-U \Psi_{x}\right)\left(\Psi_{t}+U \Psi_{x}\right) R \cos \theta} d \theta\right. \\
& -\frac{\rho g}{2} \oint_{C_{F}} \overline{\tilde{\zeta}^{2}} d y+\rho U \oint_{C_{F}} \overline{\tilde{\zeta} \Psi_{x}} d y
\end{aligned}
$$

となる。但し，(17)式において $S_{c_{0}}$ 境界面上で $\partial / \partial n=$ $-\partial / \partial R, n_{x}=-\cos \theta$ の関係を用いている。(17)式を時間平 均を行なって整理し, 無限遠での速度ポテンシャルの漸近 形を用いて展開し, Appendix A2 のエネルギー原理によつ て得られた関係を用いて変形すると, 結局 $z \leq 0$, 即ち固定 境界における抵抗増加 $\Delta R^{\prime}$ は次式から計算できる。

$$
\begin{aligned}
\Delta R^{\prime} \equiv & \iint_{S_{H 0}} \overline{\left(P-P_{0}\right) n_{x}} d S \\
= & \frac{\rho}{8 \pi} \int_{\alpha_{0}}^{2 \pi-\alpha_{0}}\left|H\left(k_{1}, \alpha\right)\right|^{2} \\
& \operatorname{sgn}(\cos \alpha) \frac{k_{1}\left(k_{1} \cos \alpha-K \cos \chi\right)}{\sqrt{1-4 \tau \cos \alpha}} d \alpha \\
& +\frac{\rho}{8 \pi} \int_{\alpha_{0}}^{2 \pi-\alpha_{0}}\left|H\left(k_{2}, \alpha\right)\right|^{2} \frac{k_{2}\left(k_{2} \cos \alpha-K \cos \chi\right)}{\sqrt{1-4 \tau \cos \alpha}} d \alpha \\
& -\frac{\rho U}{4 g} \oint_{C_{F}}\left\{i \omega_{e}\left(\phi \frac{\partial \phi^{*}}{\partial x}-\phi^{*} \frac{\partial \phi}{\partial x}\right)-2 U \frac{\partial \phi}{\partial x} \frac{\partial \phi^{*}}{\partial x}\right\} d y \\
+\omega \cos & \chi \frac{\rho U}{4 g^{2}} \oint_{C_{F}}\left\{i \omega_{e} U\left(\phi \frac{\partial \phi^{*}}{\partial x}-\phi^{*} \frac{\partial \phi}{\partial x}\right)-2 \omega_{e}^{2} \phi \phi^{*}\right\} d y \\
& -\frac{\rho}{4 g} \oint_{C_{F}}\left|\left(i \omega_{e}-U \frac{\partial}{\partial x}\right) \phi\right|^{2} \cdot n_{x} d C
\end{aligned}
$$

但し, $\rho$ は密度, $g$ は重力加速度, * は共役複素数を表わす。 (18)式は左辺, 即ち直接圧力積分が右辺の式の值と等しい ことを表わしており，間接的に抵抗増加計算の validity 検討するための関係となっている。

\section{2 抵抗増加}

(18)式は validation のために $z \leq 0$ の水面下部に働く流 体力の関係を表わしたものであり，実際の抵抗増加は前述 のように $S_{H}$ の上の圧力を積分したものでなければならな いが，これまでの議論から判るように，これは(12)，(16), (18)式の両辺に, wave elevation による圧力変動の影響を 加味することによって得られる。

まず定常造波抵抗は

$$
R_{0}=R_{0}^{\prime}+\oint_{C_{F}} d l \int_{0}^{\zeta_{0}} P_{0} n_{x} d z
$$

になり，また同様に非定常造波抵抗は

$$
\tilde{R}=\tilde{R}^{\prime}+\oint_{C_{F}} d l \overline{\int_{0}^{5} P n_{x} d z}
$$

のように書くことができる。式(19)，(20)に（5），（6）， (9)，(12)，（16)式を代入し整理すると抵抗増加は次式の ようになる。

$$
\begin{gathered}
\Delta R=\frac{\rho}{8 \pi} \int_{\alpha_{0}}^{2 \pi-\alpha_{0}}\left|H\left(k_{1}, \alpha\right)\right|^{2} \\
\operatorname{sgn}(\cos \alpha) \frac{k_{1}\left(k_{1} \cos \alpha-K \cos \chi\right)}{\sqrt{1-4 \tau \cos \alpha}} d \alpha \\
+\frac{\rho}{8 \pi} \int_{\alpha_{0}}^{2 \pi-\alpha_{0}}\left|H\left(k_{2}, \alpha\right)\right|^{2} \frac{k_{2}\left(k_{2} \cos \alpha-K \cos \chi\right)}{\sqrt{1-4 \tau \cos \alpha}} d \alpha \\
-\frac{\rho U}{4 g} \oint_{C_{F}}\left\{i \omega_{e}\left(\phi \frac{\partial \phi^{*}}{\partial x}-\phi^{*} \frac{\partial \phi}{\partial x}\right)-2 U \frac{\partial \phi}{\partial x} \frac{\partial \phi^{*}}{\partial x}\right\} d y \\
+\omega \cos \chi \frac{\rho U}{4 g^{2}} \oint_{C_{F}}\left\{i \omega_{e} U\left(\phi \frac{\partial \phi^{*}}{\partial x}-\phi^{*} \frac{\partial \phi}{\phi x}\right)-2 \omega_{e}^{2} \phi \phi^{*}\right\} d y
\end{gathered}
$$

(21) 式は丸尾教授の抵抗増加公式に余分な項(第 3，4 項) が付いた形になっているが，これらの項は速度が 00 場合 及び, thin ship theory の仮定では消える。即ち, consistent な理論ではこのような余分な項は生じず，丸尾教授の抵抗 増加公式と完全に一致する。従って，これらの付加項は Neumann-Kelvin 問題の不斉合性によって生じたものと 考えられる。

\section{3. 圧力積分による抵抗増加}

\section{1 固定境界に作用する抵抗増加}

波動場における物体に働く流体力は物体表面に作用する 圧力から求めることができ，固定境界 $S_{H_{0}}$ に働く抵抗増加 は(18)式左辺より

$$
\begin{aligned}
\Delta R^{\prime} & \equiv \iint_{S_{H O}}\left(P-P_{0}\right) n_{x} d S \\
& =-\frac{\rho}{2} \iint_{S_{H O}}(\nabla \Psi)^{2} n_{x} d S \\
& =-\frac{\rho}{4} \iint_{S_{H 0}}\left(\nabla \phi \cdot \nabla \phi^{*}\right) n_{x} d S
\end{aligned}
$$

のようになる。

\section{2 抵抗増加}

物体表面上での水面変位を考慮した移動境界 $S_{H}$ に働く $x$ 方向の流体力と定常力即ち，抵抗増加はそれぞれ次式か ら計算できる。

$$
\begin{aligned}
F_{x}= & \rho \iint_{S_{H}}\left(i \omega_{e}-U \frac{\partial}{\partial x}\right) \phi n_{x} d S \\
\Delta R= & \Delta R^{\prime}+\frac{\rho g}{2} \oint_{C_{F}} \overline{\tilde{\zeta}^{2} n_{x}} d C \\
= & \frac{\rho}{4 g} \oint_{C_{F}}\left|\left(i \omega_{e}-U \frac{\partial}{\partial x}\right) \phi\right|^{2} n_{x} d C \\
& -\frac{\rho}{4} \iint_{S_{H O}}\left(\nabla \phi \cdot \nabla \phi^{*}\right) n_{x} d S
\end{aligned}
$$

\section{4. 数值計算結果及び考察}

\section{1 計算と実験に用いた模型}

本研究の内容は特に低速に限定するものではないが, 著 者等の以前の研究 ${ }^{11}$ の計算の精度を検討する意味で, Fig. 3 
のような海洋構造物の column を想定した鉛直円柱が低速 で航行する場合の計算を行なうことにした。また実験は以 前の研究で行なったものがあるが7), 実験解析に誤りのあ ることが確認されたので, 今回再実験を行なった。

\section{2 結果及び考察}

積分方程式法によって解を求める際に，核関数となるグ リーン関数の積分精度に対する検討は以前著者らによって なされており ${ }^{4)}$, その結果, 本計算模型についてはパネルの 切り方は水面に接するパネルを喫水の $1 / 1000$ 程度にすれ ばよいことが判っており, Fig. 3 に示すように半面 74 分割 にして計算を行った。

積分方程式を解いた解を用いて物体浸水表面での圧力積 分から求めた抵抗増加と運動量理論を使った抵抗増加との 差異を調查する意味で，前述のように本来の抵抗増加では ないが計算結果の妥当性を検討するため, まず $z=0$ 以下

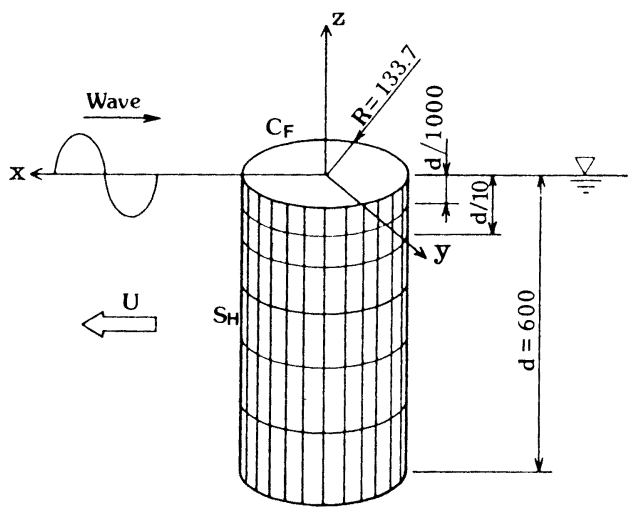

Fig. 3 Panel division of model
の境界面，即ち固定境界における抵抗増加である (18)式と (22) 式による結果の比較を Fig. 4 と Tables 1，2 に示す。 Fig. 4 は横軸に波長と円筒長径の比 $(\lambda / D)$ をとり, 縦軸に 各々の方法で求めた固定境界に働く抵抗増加の無次元值を

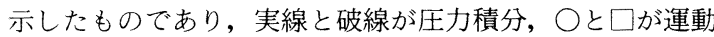
量理論を用いた結果である。また Tables 1, 2 は各々 Fn= 0.0001 と 0.06 の場合の直接圧力積分と運動量理論による 結果の差異を百分率で示した表である。図から判るように $F n=0.0001,0.06$ ともに波長が短い所ではよく一致し $5 \%$ 以内の誤差であるが，波長が長くなると抵抗増加の無次元 值が相対的に小さくなり，わずかの䛊差が error として大 きく評価されるので，さらに精密な計算を行なう必要があ る。

実際の流体力計算においては波面変化の効果を考慮しな ければならず，それによる計算を $F n=0.0,0.02,0.04,0.06$, 0.08 の向波状態で行った。上記速度に対応した一次の流体 力振幅を Figs. $5 ， 7 ， 9 ， 11 ， 13$ に実験結果とともに示す。

Table 1 Added resistance coefficient $(F n=0.0001)$

\begin{tabular}{|c|ccc|ccc|}
\hline \multirow{2}{*}{$\lambda / \mathrm{D}$} & \multicolumn{3}{|c|}{$\Delta \mathrm{R}^{\prime}$} & \multicolumn{3}{c|}{$\Delta \mathrm{R}$} \\
\cline { 2 - 7 } & Pressure & Momentum & Error $(\%)$ & Pressure & Momentum & Error(\%) \\
\hline 3.0 & -0.3648 & -0.3540 & 2.8 & 0.6665 & 0.6773 & 1.6 \\
5.0 & -0.2146 & -0.2178 & 1.2 & 0.4662 & 0.4629 & 0.8 \\
7.0 & -0.1115 & -0.1175 & 5.2 & 0.2355 & 0.2295 & 2.4 \\
9.0 & -0.0607 & -0.0655 & 7.6 & 0.1239 & 0.1191 & 3.6 \\
\hline
\end{tabular}

Table 2 Added resistance coefficient $(F n=0.06)$

\begin{tabular}{|c|ccc|ccc|}
\hline \multirow{2}{*}{$\lambda / \mathrm{D}$} & \multicolumn{3}{|c|}{$\Delta \mathrm{R}^{\prime}$} & \multicolumn{3}{c|}{$\Delta \mathrm{R}$} \\
\cline { 2 - 7 } & Pressure & Momentum & Error $(\%)$ & Pressure & Momentmu & Error $(\%)$ \\
\hline 3.0 & -0.3325 & -0.3127 & 6.1 & 0.7108 & 0.7306 & 2.7 \\
5.0 & -0.2387 & -0.2514 & 5.1 & 0.6480 & 0.6352 & 2.0 \\
7.0 & -0.1404 & -0.1592 & 12.5 & 0.3505 & 0.3316 & 5.5 \\
9.0 & -0.0808 & -0.1006 & 20.1 & 0.1894 & 0.1696 & 11.0 \\
\hline
\end{tabular}

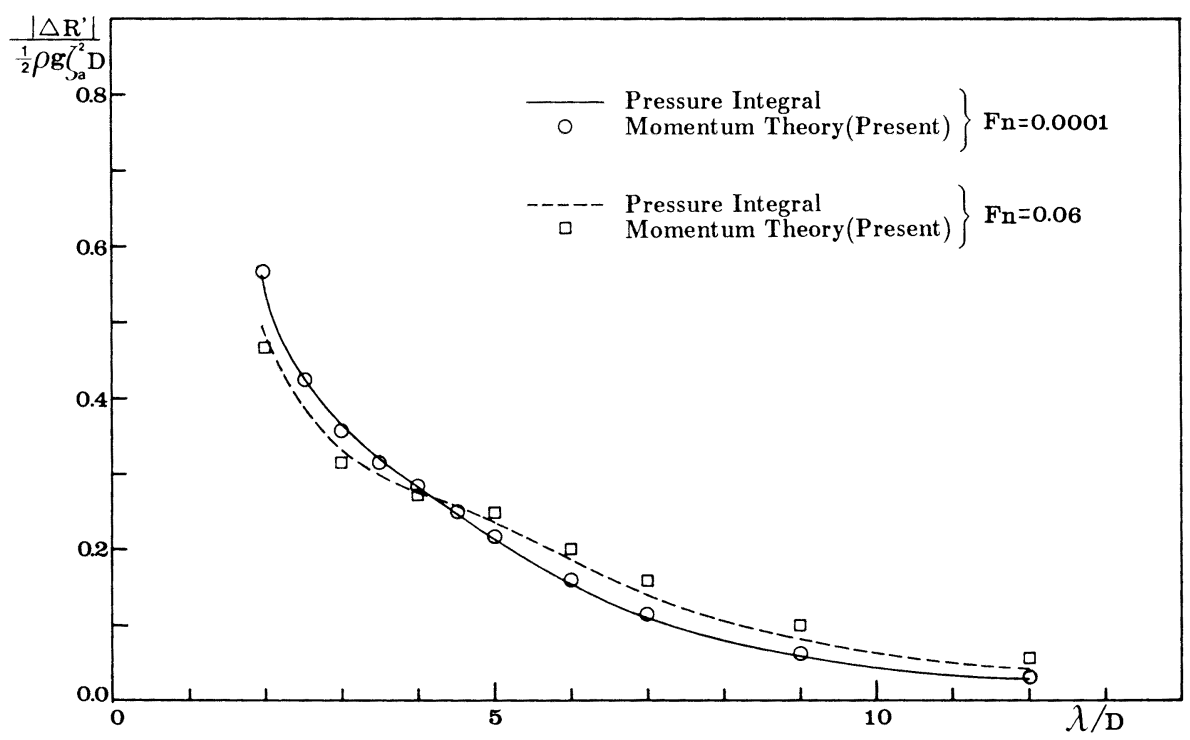

Fig. 4 Added resistance acting on the model under $z=0(\chi=180)$ 


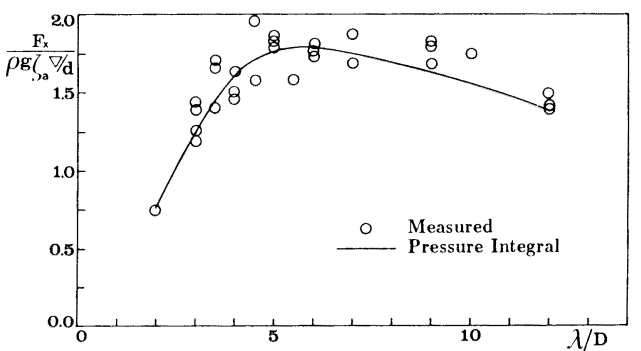

Fig. 5 Wave exciting force in head waves $(F n=0.0, \chi=180)$

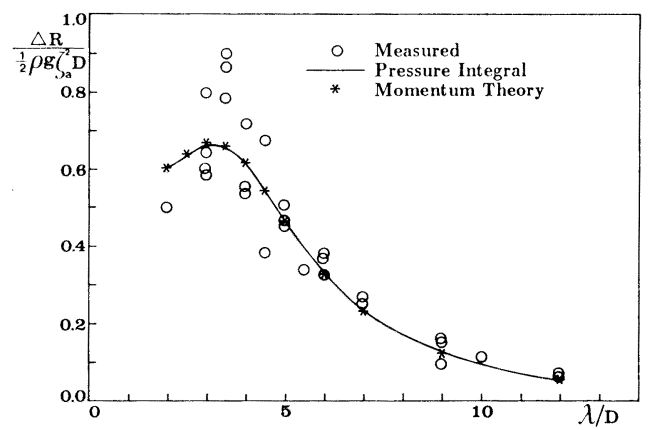

iig. 6 Drift force in head waves $(F n=0.0, \chi=180)$

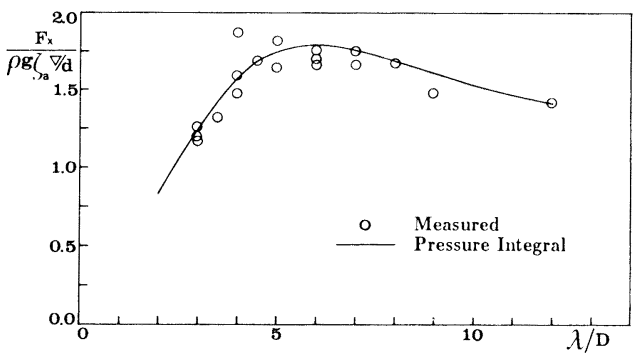

Fig. 7 Wave exciting force in head waves $(F n=0.02, \chi=180)$

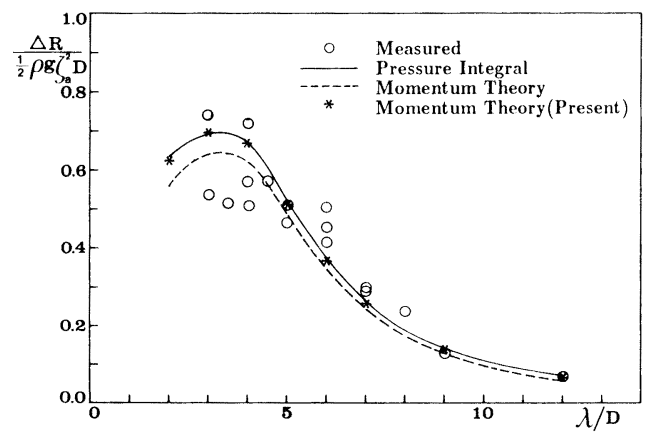

Fig. 8 Added resistance coefficient in head waves $(F n=0.02, \chi=180)$

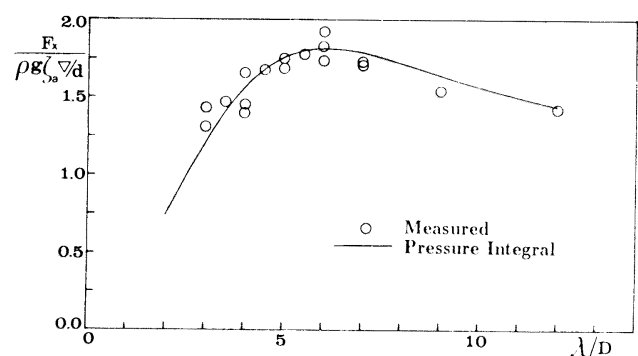

Fig. 9 Wave exciting force in head waves $(F n=0.04, \chi=180)$

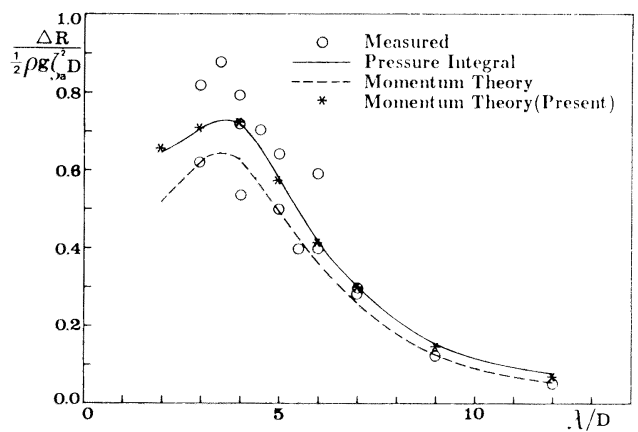

Fig. 10 Added resistance coefficient in head waves $(F n=0.04, \chi=180)$

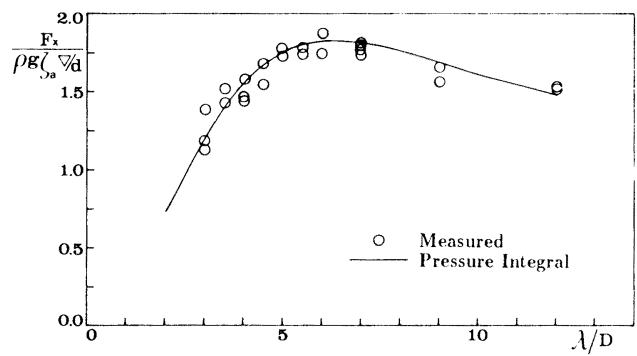

Fig. 11 Wave exciting force in head waves $(F n=0.06, \chi=180)$

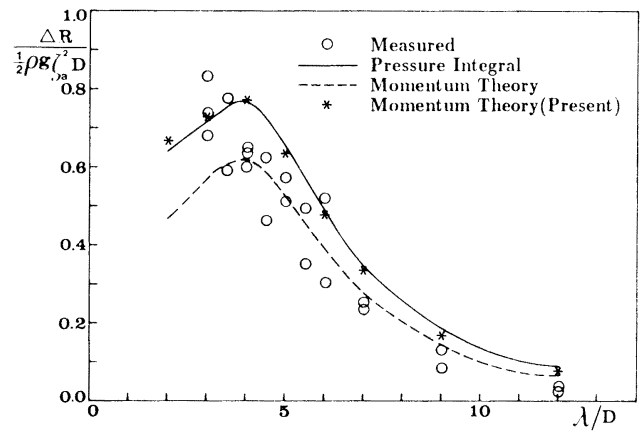

Fig. 12 Added resistance coefficient in head waves $(F n=0.06, \chi=180)$ 


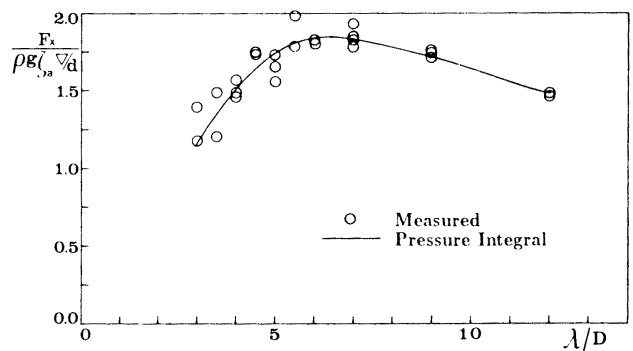

Fig. 13 Wave exciting force in head waves $(F n=0.08, \chi=180)$

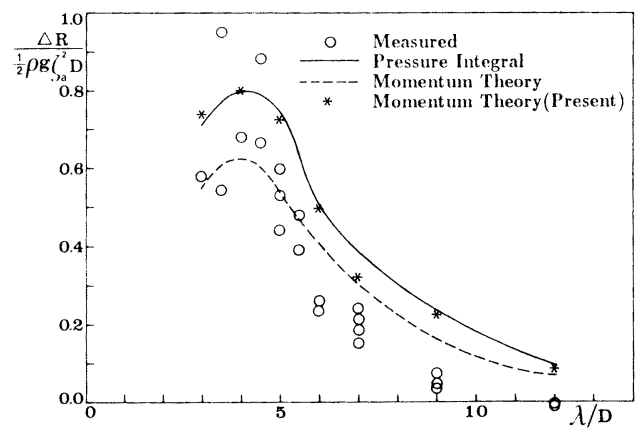

Fig. 14 Added resistance coefficient in head waves $(F n=0.08, \chi=180)$

後の抵抗増加と同様，横軸には波長と円筒直径の比 $\lambda / D$ を とり，縦軸に流体力振幅の無次元值をとっている。これら の計算結果は実験と良好な一致を示している。

次に抵抗增加に関する結果を Figs. $6,8,10 ， 12 ， 14$ に 示す。各図に抢いて○印は実験結果であり，破線は(21) 式 において第 3 項，第 4 項を除いた丸尾教授の抵抗増加公式 によって計算した結果を示し，実線は圧力積分によって得 られた結果を，また*印は(21) 式，即ち Neumann-Kelvin 問題の不斉合性によるものと思われる付加項を考慮した式 によって計算した結果を示す。前述のように(21)式におい て，付加項は速度が 0 になると消え，丸尾教授の抵抗増加 の公式と等しくなるが，Fig. 6 よりその計算結果は压力積 分と非常によく一致し，実験との一致度も良好である。即 ち, consistent な理論においては直接圧力積分と丸尾教授 の抵抗増加の結果は一致し,理論の正当性が証明されるが, Neunmann-Kelvin 問題等の inconsistent な理論を取り扱 う場合には注意を要する。このことは，Figs. 8，10，12， 14 のような速度がある場合にはれ尾教授の抵抗増加の公 式によって得た結果と直接压力積分とは一致せず，この差 異は(21) 式のように不斉合性を考慮することによってうめ られることからわかる。また，別の言い方をすると本研究 における直接圧力積分法は (21) 式の運動量理論によって得 た結果と一致しており，精度よく計算できていると考えら
れる。ただし, Table 1 からわかるように速度が速くなつ た場合の長波長の領域で, 計算の精度が悪く, Figs. 8, 10, $12 ， 14$ で明らかなように，この領域で実験との一致が良く ない。今後さらに計算精度の向上を検討する必要がある。

以上のことは計算の validation という観点からの結果 を論じたものであり，あくまでNeumann-Kelvin 問題とい う不斉合性をはらんだ理論の上で精度良く計算できたかど うかの検討であることに注意する必要がある。即ち，抵抗 増加等の 2 次の流体力を扱う場合には，オーダーが厳密に 評価できる consistent な理論を用いて計算する必要があ ると思われる。

\section{結言}

Neumann-Kelvin 問題に抢いて抵抗増加を計算する場 合, 計算の validationのよりどころとなる理論の展開を試 みた。その結果 Neumann-Kelvin 問題のような inconsistent な理論を取り扱う場合には，運動量理論の展開におい て丸尾教授の抵抗増加公式に上記の inconsistency に寄因 する付加項が必要になることがわかった。また数値計算に よってその項の寄与度を調査したところ，無視できないも のであることもわかった。さらに，この付加項を考慮する ことによって直接圧力積分した結果とよく一致し，これに よって Neumann-Kelvin 問題を取り扱った計算の精度を 評価することができると考えられる。本研究の計算結果は 速度が速くなると上記の精度が悪くなっており，さらに計 算の精度向上の試みをする必要がある。

本研究遂行に際して, 貴重な御議論をいただいた広島大 学工学部教授高木幹雄先生に感謝の意を表します。また, 同助手岩下英嗣先生には計算プログラム作成に関して多大 な援助を賜りました。この場を借りて感謝いたします。尚， 本研究の計算は Apollo-DN 10000 にって行ったことを 附記する。

\section{参 考 文 献}

1）肥後 靖, 河 文根, 許平：波浪中を低速航行する 鉛直円柱に働く流体力に関する研究，関西造船協会 誌，第 214 号(1990)，81-87

2) Maruo, H. : Resistance in Waves, 60th Aniversory Series, Vol. 8, The Society of Naval Arch. of Japan (1963), 68-91

3) Faltinsen, O. M., Minsaas, K. J., Liapis, N., Skjordal, S. O.: Prediction of Resistance and Propulsion of a Ship in a Seaway, Proc. 13th Symposium on Naval Hydrodynamics (1980), 505-529

4）肥後 靖, 河 文根：前進速度を有する物体の動摇 問題における線積分に関する一考察, 関西造船協会 誌，第 215 号掲載予定

5) Kashiwagi, M., Ohkusu, M.: The Effect of Forward speed in the Radiation Problem of a Surface-Piercing Body, J. Soc. Naval Arch. 
Japan, Vol. 164 (1988), 92-104

6) 肥後 靖, 高木又男：動摇問題における変位影響に 関する捸動論的考察, 日本造船学会論文集, 第 164 号 (1988)，105-110

7）肥後 靖，佐藤和彦：波浪中を低速航行する鉛直円 柱に働く抵抗増加に関する研究，日本造船学会論文 集，第 163 号 (1987)，219-227

8）肥後 靖, 河 文根：波浪中を航行する固定物体に 働く抵抗増加について, 第 23 回運動性能研究委員会 資料(1990)

\section{付}

\section{録}

A 1. Neumann-Kelvin 問題における流量の連続性に ついて

Fig. 1 のように波浪中を物体が前進する問題について考 える。境界面としては固定境界を採用すると Fig. 1, Fig. 2 において $S_{C_{0}}, S_{F_{0}}, S_{H_{0}}$ に囲まれた領域において境界は固定 壁であるから，単位時間当り流入する流体質量 $W$ は

$$
W=\rho \iint_{S_{c o}} \frac{\partial \Phi}{\partial n} d S-\rho \iint_{S_{F 0}} \frac{\partial \Phi}{\partial z} d S
$$

と表わされ, 速度ポテンシャル (2) 式と自由表面条件 (4) 式によって， $S_{F_{0}}$ 上での積分を書き換えると

$$
\begin{gathered}
W=\rho \iint_{S_{c 0}} \frac{\partial \Phi}{\partial n} d S+\rho \iint_{S_{F 0}}\left\{\frac{U}{K_{0}} \varphi_{x x}+\frac{1}{g}\left(\Psi_{t t}\right.\right. \\
\left.\left.-2 U \Psi_{t x}+U^{2} \Psi_{x x}\right)\right\} d S
\end{gathered}
$$

を得る。ここで(A 1.2)の両辺の時間平均をとると, $\Psi$ の周 期性と $S_{F_{0}}$ が固定境界であることから

$$
\bar{W}=\rho \overline{\iint_{S_{c 0}} \frac{\partial \Phi}{\partial n}} d S+\frac{\rho U}{K_{0}} \iint_{S_{F 0}} \varphi_{x x} d S
$$

になり, 流量の保存性から流入流体の一周期平均は 0 とな るので

$$
\rho \overline{\iint_{S_{c 0}} \frac{\partial \Phi}{\partial n}} d S=-\frac{\rho U}{K_{0}} \iint_{S_{F 0}} \varphi_{x x} d S
$$

の関係が成立する。

次に定常問題の流量保存についても同様に単位時間当り 流入する流体質量 $W_{0}$ は

$$
W_{0}=\rho \iint_{S_{c 0}} \frac{\partial \Phi_{0}}{\partial n} d S+\frac{\rho U}{K_{0}} \iint_{S_{F 0}} \varphi_{x x} d S
$$

のようになり, 流量の保存性から $W_{0}$ は 0 となるので以下 の関係を得る。

$$
\rho \iint_{S_{c 0}} \frac{\partial \Phi_{0}}{\partial n} d S=-\frac{\rho U}{K_{0}} \iint_{S_{F 0}} \varphi_{x x} d S
$$

(A 1.4), (A 1.6)式において右辺の自由表面上での積分は Stokes の定理を用いると, 定常問題における流量の保存は

$$
\begin{aligned}
\rho \iint_{S_{c 0}} \frac{\partial \Phi_{0}}{\partial n} d S & =\frac{\rho U}{K_{0}}\left[\oint_{C_{F}} \varphi_{x} d y-\oint_{C_{\infty}} \varphi_{x} d y\right] \\
& =\rho U\left[\oint_{C_{F}} \zeta_{0} d y-\oint_{C_{\infty}} \zeta_{0} d y\right]
\end{aligned}
$$

のようになり, 同様に非定常問題における流量の保存は次 式のように表わせる。

$$
\rho \overline{\iint_{S_{C 0}} \frac{\partial \Phi}{\partial n}} d S=\frac{\rho U}{K_{0}}\left[\oint_{C_{F}} \varphi_{x} d y-\oint_{C_{\infty}} \varphi_{x} d y\right]
$$

$$
=\rho U\left[\oint_{C_{F}} \zeta_{0} d y-\oint_{C_{\infty}} \zeta_{0} d y\right]
$$

\section{A 2. エネルギー原理}

二次元のエネルギー原理については柏木によって明らか にされている4)のでここでは三次元の場合について考え る。Fig. 1 のような境界面 $S$ によって囲まれた領域 $V$ で のエネルギー変化率は

$$
\frac{d E}{d t}=\rho \iiint_{v} \frac{\partial}{\partial t}\left[\frac{1}{2} v^{2}+g z\right] d v-\rho \iint_{S}\left[\frac{1}{2} v^{2}+g z\right] U_{n} d S
$$

と表わせる。ここで $v$ は流体粒子の速度べクトルである。 (A 2.1) を Bernoulli 圧力方程式とGauss の定理を適用し て書き換えると

$$
\begin{aligned}
\frac{d E}{d t} & =\rho \iiint_{V} \operatorname{div}\left[\Phi_{t} \operatorname{grad} \Phi\right] d v+\rho \iint_{S}\left[\frac{P}{\rho}+\frac{\partial \Phi}{t}\right] \dot{U}_{n} d S \\
& =-\rho \iint_{S}\left[\frac{\partial \Phi}{\partial t} \frac{\partial \Phi}{\partial n}-\left(\frac{P}{\rho}+\frac{\partial \Phi}{\partial t}\right) U_{n}\right] d S \text { (A 2.2) }
\end{aligned}
$$

を得る。このエネルギ一関係式を固定境界について考える と, 境界条件としては本文 $(7$ ) 式のようになり (A 2.2) 式 は

$$
\frac{d E}{d t}=-\rho \iint_{S_{c 0}} \frac{\partial \Phi}{\partial t} \frac{\partial \Phi}{\partial n} d S+\rho \iint_{S_{r_{0}}} \frac{\partial \Phi}{\partial t} \frac{\partial \Phi}{\partial z} d S
$$

と書け，両辺の周期平均をとると

$$
\begin{aligned}
0= & -\rho \int_{0}^{2 \pi} R d \theta \int_{-\infty}^{0} \overline{\frac{\partial \Psi}{\partial t}\left[U\left(-n_{x}+\varphi_{n}\right)+\Psi\right]} d z \\
& +\rho \iint_{S_{F 0}} \overline{\Psi_{t}\left[-\frac{U}{K_{0}} \varphi_{x x}-\frac{1}{g}\left(\Psi_{t t}-2 U \Psi_{t x}\right.\right.} \\
& \left.\left.+U^{2} \Psi_{x x}\right)\right] d S
\end{aligned}
$$

となる。ここで

$$
\left.\begin{array}{l}
\Psi_{t} \Psi_{t x}=\frac{1}{2} \frac{\partial}{\partial x}\left(\Psi_{t} \Psi_{t}\right) \\
\Psi_{t} \Psi_{x x}=\frac{\partial}{\partial x}\left(\Psi_{t} \Psi_{x}\right)-\Psi_{t x} \Psi_{x}
\end{array}\right\}
$$

であることと，周期性を利用して（A 2.4）を書き換えると

$$
\begin{aligned}
0= & -\rho \int_{0}^{2 \pi} R d \theta \int_{-\infty}^{0} \overline{\Psi_{t} \Psi_{n}} d z \\
& -\frac{\rho}{g} \iint_{S_{F 0}} \overline{\left[\Psi_{t} \Psi_{t t}-U \frac{\partial}{\partial x}\left\{\Psi_{t} \Psi_{t}-U \Psi_{t} \Psi_{x}\right\}\right.} \\
& \left.\left.-U^{2} \Psi_{t x} \Psi_{x}\right)\right] d S
\end{aligned}
$$

のようになるが, 非定常攪乱ポテンシャルの微分項には

$$
\overline{\Psi_{t} \Psi_{t t}}=\overline{\Psi_{t x} \Psi_{x}}=0
$$

の関係があり，さらに自由表面上ではStokes 定理を適用 すると(A 2.6)式は

$$
\begin{aligned}
0= & -\rho \int_{0}^{2 \pi} R d \theta \int_{-\infty}^{0} \overline{\Psi_{t} \Psi_{n}} d z-\rho U\left[\oint_{C_{\infty}} \overline{\tilde{\zeta} \Psi_{t}} d y\right. \\
& \left.-\oint_{C_{\digamma}} \overline{\xi \Psi_{t}} d y\right]
\end{aligned}
$$

のように表せる。また検査面 $S_{C o}$ 上では 
$d y=d l \cos \theta=-n_{x} d l=-n_{x} R d \theta$

の関係があり, 結局次式のようなエネルギー関係式が得ら

れる。

$$
\begin{aligned}
& -\rho \int_{-\infty}^{0} d z \int_{0}^{2 \pi} \overline{\Psi_{t} \Psi_{n} R} d \theta+\rho U \int_{0}^{2 \pi} \overline{\tilde{\zeta} \Psi_{t}} R n_{x} d \theta \\
& =-\rho U \oint_{C_{F}} \overline{\tilde{\zeta} \Psi_{t}} d y
\end{aligned}
$$

